\title{
Research on Quality Control of Precision Machining Straight Internal Gear by Abrasive Flow Based on large Eddy Simulation
}

\section{Tiangang Zou}

Beijing Institute of Technology $₫$ Beijing

Qingdong Yan ( $\square$ zdmjournal@163.com )

Beijing University of Technology

\section{Lixiong Wang}

China North Vehicle Research Institute Key Laboratory of Vehicle Transmission

\section{Yuanyuan AN}

Changchun University of Science and Technology, Changchun

\section{Jiyong qu}

Changchun University of Science and Technology, Changchun

junye li

Changchun University of Science and Technology, Changchun

\section{Research Article}

Keywords: abrasive flow, large eddy simulation, gear, orthogonal experiment

Posted Date: September 16th, 2021

DOl: https://doi.org/10.21203/rs.3.rs-893547/v1

License: (1) This work is licensed under a Creative Commons Attribution 4.0 International License. Read Full License

Version of Record: A version of this preprint was published at The International Journal of Advanced Manufacturing Technology on January 15th, 2022. See the published version at https://doi.org/10.1007/s00170-021-08453-w. 


\title{
Research on quality control of precision machining straight internal gear by abrasive flow based on large eddy simulation
}

\author{
Tiangang Zou ${ }^{1,2}$, Qingdong $\mathrm{Yan}^{1 *}$, Lixiong Wang ${ }^{3}$, Yuanyuan $\mathrm{An}^{2}$, Jiyong $\mathrm{Qu}^{3}$, Junye $\mathrm{Li}^{3}$ \\ 1 Beijing Institute of Technology, Beijing 100081, China \\ 2 China North Vehicle Research Institute Key Laboratory of Vehicle Transmission, Beijing 100072 , \\ China \\ 3 Ministry of Education Key Laboratory for Cross-Scale Micro and Nano Manufacturing, \\ Changchun University of Science and Technology, Changchun 130022, China
}

\begin{abstract}
Traditional finishing technology is difficult to realize the precision machining of complex geometric parts. Abrasive flow machining technology solves this problem well. Taking the spur internal gear as the research object, the wall shear force, static pressure, dynamic pressure and abrasive velocity vector of the internal channel of the straight internal gear under different inlet velocity, abrasive concentration and abrasive particle size are analyzed by using the large eddy simulation method, and the action law of different parameters on the machining of straight internal gear by solid-liquid two-phase abrasive flow is discussed. At the same time, orthogonal test was carried out. The results show that the solid-liquid two-phase abrasive flow machining technology can effectively remove the burrs, pits and bulges on the tooth surface of spur internal gear, reduce the tooth surface roughness and improve the surface quality. The optimal combination of processing parameters and the primary and secondary order of various factors affecting processing are obtained by range analysis and analysis of variance. The regression equation is constructed by regression analysis to verify the effectiveness and accuracy of the model, which provides theoretical support and data reference for actual processing and production.
\end{abstract}

Keywords: abrasive flow; large eddy simulation; gear; orthogonal experiment;

\section{Introduction}

Internal gear pair has been widely used in gearbox. Due to the ratio of low contact stress and high contact to external gear pair, gear profile plays an important role in transmission [1]. The

* Corresponding author : Qingdong Yan

E-mail: zdmjournal@163.com, +86-17843363055 
surface accuracy of the internal tooth surface directly affects the working performance of relevant products. Although the traditional finishing processes such as grinding, grinding and manual polishing can meet the accuracy requirements of mechanical parts, they have low efficiency, high cost and high noise. So the traditional finishing processes are not suitable for machining mechanical parts with complex geometry [2-3]. Abrasive flow machining technology takes the fluid as the carrier, mixes the self sharpening solid abrasive particles into it, and prepares the abrasive suitable for machining. By squeezing the semi-solid fluid abrasive into the flow channel formed by the workpiece and supporting fixture, it flows back and forth to achieve the purpose of polishing, deburring, rounding and removing the recast layer, and finally obtain the workpiece with highprecision inner surface. It can successfully solve the problem of precision polishing of mechanical parts with complex geometry [4-6].

In recent years, AFM process has been continuously improved, and has been widely concerned and applied due to its advantages of high polishing efficiency, high adaptability and low workpiece damage rate [7-9]. Duval MS et al [10] took the inner surface roughness of selective laser melting parts as the research object, discussed the machining effects of different media and abrasive concentration on the initial surface, and verified the influence of abrasive flow medium on abrasive surface roughness. Munhoz MR et al [11] used the developed new slurry and traditional industrial slurry as abrasives to process the surfaces of SAE 1045 steel and 6061 T6 aluminum workpieces. The results show that the newly developed slurry can reduce the surface roughness of the workpiece. Tang et al [12] optimized the traditional abrasive flow machining technology, formulated the tool rotation machining scheme, and analyzed the effects of different abrasive concentration, tool rotation and other factors on the tool surface finish and tool cutting performance by using the orthogonal experimental method to verify the impact of the process on the tool surface.

Combining computational fluid dynamics knowledge with finite element analysis software to carry out numerical simulation, analysis and prediction is one of the modern engineering technology means. Large eddy simulation is the first mock exam for numerical simulation of vortex with different scales in turbulent state. Large scale eddy is solved accurately and small scale eddy is unified and modeled as sub-grid model $[13,14]$. Compared with other numerical simulation methods, large eddy simulation method has the outstanding advantages of small amount of calculation and high accuracy, and can characterize many unsteady phenomena. Bouland C et al [15] simulated the 
indentation of abrasive on the workpiece, and experimentally studied the Ti-6Al-4V sample fused by laser powder bed. The results show that the simulation and experiment provide very close results in terms of material removal, and the relatively small differences observed can be reduced by improving the calibration scheme and adjusting the boundary conditions of the model. Li et al [1618] studied the collision between abrasive particles in abrasive flow machining process and the influence of common machining parameters on machining effect, and verified and analyzed it by using large eddy simulation method to verify the effectiveness of abrasive flow machining and the efficiency of numerical analysis. Ramí rez-Cruz et al [19] used the large eddy simulation method to study the free surface flow in a turbine-driven unbaffled stirred tank, and used a compact difference scheme and level set method to solve the flow equation and track the free surface. The results show that the liquid level has a good consistency, and the wake vortex behind the impeller blades and other important turbulent structures moving above the impeller and near the critical radius are observed. Long Y et al [20] used large eddy simulation (LES) to simulate the turbulent cavitation flow around conventional propeller and highly inclined marine propeller (HSP), focusing on the influence of inclination angle. The influence of cavitation on flow structure is verified by large eddy simulation. The results show that the error of large eddy simulation method for highly inclined marine propeller is less than that of conventional propeller.

Based on the large eddy numerical simulation method, taking the spur internal gear as the research object, this paper numerically studies the processing law of solid-liquid two-phase abrasive flow of spur internal gear with parameters such as abrasive inlet velocity, abrasive concentration and particle size, and carries out experimental processing and inspection of spur internal gear. Referring to the numerical simulation results, The optimal machining combination of straight internal gear by solid-liquid two-phase abrasive flow precision machining technology is discussed.

\section{Large eddy numerical simulation theory}

\subsection{The basic idea of large eddy numerical simulation}

The main idea of large eddy numerical simulation is to decompose turbulence into solvablescale turbulence (including large-scale pulsations) and unsolvable-scale turbulent motion (including all small-scale motions) through a filter. The solvable-scale turbulence motion is directly carried 
out by numerical calculation methods. To solve, the effect of small-scale turbulent pulsation energy, momentum and mass transport on large-scale motion is modeled (called sub-grid model), so that the solvable scale motion equation is closed. Since the flow boundary has little influence on smallscale pulsations, the sub-grid model may have good applicability to a wide range of complex turbulent motions.

\subsection{Energy equation}

The essence of the law of conservation of energy as a basic law that all heat exchange fluid systems must satisfy is the first law of thermodynamics. The expression of the energy equation is:

$$
\frac{\partial(\rho \mathrm{E})}{\partial \mathrm{t}}+\nabla \cdot[\overrightarrow{\mathrm{u}}(\rho \mathrm{E}+\mathrm{p})]=\nabla \cdot\left[\mathrm{k}_{\mathrm{eff}} \nabla \mathrm{T}-\sum_{\mathrm{j}} h_{j} \mathrm{~J}_{\mathrm{j}}+\left({ }^{\tau}{ }_{\text {eff }} \cdot \overrightarrow{\mathrm{u}}\right)\right]+S_{h}
$$

Where: $E$ is the total energy of fluid clusters, $\mathrm{J} / \mathrm{kg}$ including the sum of potential energy, internal energy and kinetic energy; $E=h-p / \rho+u^{2} / 2 ; h$ is the enthalpy; $h_{j}$ is the enthalpy of the component; $k_{\text {eff }}$ is the effective heat transfer coefficient, and $W /(m \cdot K), k_{\text {eff }}=k+$ $k_{t}, k_{t}$ is the turbulent heat transfer coefficient, which requires specific turbulence The model is determined; $J_{j}$ is the diffusion flux of the component $j ; S_{h}$ is composed of the chemical reaction heat and the user-defined volume heat source term.

\subsection{Large eddy simulation control equations}

During the processing of solid-liquid two-phase abrasive particle flow, the fluid is usually regarded as an incompressible fluid. Taking the N-S equation as the governing equation, the expressions of the continuity equation and the momentum equation are respectively:

$$
\begin{gathered}
\frac{\partial u_{i}}{\partial x_{u}}=0 \\
\frac{\partial u_{i}}{\partial t}+u_{i} \frac{\partial u_{i}}{\partial x_{j}}=-\frac{1}{\rho} \frac{\partial p}{\partial x_{i}}+v \frac{\partial^{2} u_{i}}{\partial x_{j} \partial x_{j}}
\end{gathered}
$$

In the tableula: $v$ is the molecular viscosity coefficient.

The assumptions of filtering operation and derivation operation can be exchanged, and the following equations can be obtained by using the Navier-Stokes equation as filtering:

$$
\begin{gathered}
\frac{\partial \bar{u}_{i}}{\partial t}+\frac{\partial \overline{u_{i} u_{j}}}{\partial x_{j}}=-\frac{1}{\rho} \frac{\partial \bar{p}}{\partial x_{i}}+v \frac{\partial^{2} \bar{u}_{i}}{\partial x_{j} \partial x_{j}} \\
\frac{\partial \bar{u}_{i}}{\partial x_{u}}=0
\end{gathered}
$$

Let $\overline{u_{i} u_{j}}=\overline{u_{i}} \overline{u_{j}}+\left(\overline{u_{i} u_{j}}-\overline{u_{i}} \overline{u_{j}}\right)$, then the tableula (2-4) can be written as: 


$$
\frac{\partial \bar{u}_{i}}{\partial t}+\frac{\partial \bar{u}_{i} \bar{u}_{j}}{\partial x_{j}}=-\frac{1}{\rho} \frac{\partial \bar{p}}{\partial x_{i}}+v \frac{\partial^{2} \bar{u}_{i}}{\partial x_{j} \partial x_{j}}+\frac{\partial\left(\bar{u}_{i} \bar{u}_{j}-\overline{u_{i} u_{j}}\right)}{\partial x_{j}}
$$

Equation (2-3) has a similar table to the Reynolds equation, with an unclosed term at the right end:

$$
\overline{\tau_{i j}}=\bar{u}_{i} \bar{u}_{j}-\overline{u_{i} u_{j}}
$$

Among them, $\overline{\tau_{i j}}$ called sub-grid stress, sub-grid stress can filter out the momentum transport between small-scale pulsation and solvable-scale turbulence.

\section{Abrasive flow machining internal gear simulation analysis}

\subsection{Establishment of numerical model}

This paper takes a spur internal gear as the research object, and the specific basic parameters are shown in Table 1.

Table 1 Basic parameters of spur internal gear

\begin{tabular}{cccc}
\hline name & Parameter value & name & Parameter value \\
\hline Number of teeth $z$ & 18 & Modulus $m$ & $3 \mathrm{~mm}$ \\
pressure angle $\alpha$ & $20^{\circ}$ & Helix angle $\beta$ & 0 \\
Addendum height coefficient $h_{a}{ }^{*}$ & 1 & Tooth width $B$ & $50 \mathrm{~mm}$ \\
Head clearance coefficient $c^{*}$ & 0.25 & Addendum circle diameter $D_{a}$ & $48 \mathrm{~mm}$ \\
Tooth root circle diameter $D_{f}$ & $61.5 \mathrm{~mm}$ & Diameter of index circle $D$ & $54 \mathrm{~mm}$ \\
\hline
\end{tabular}

The three-dimensional geometric model and three-dimensional section view of the spur internal gear are shown in Figure 1.

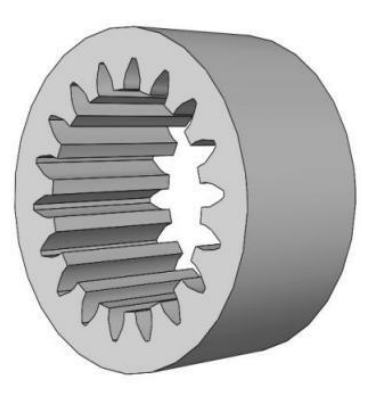

a) 3D model

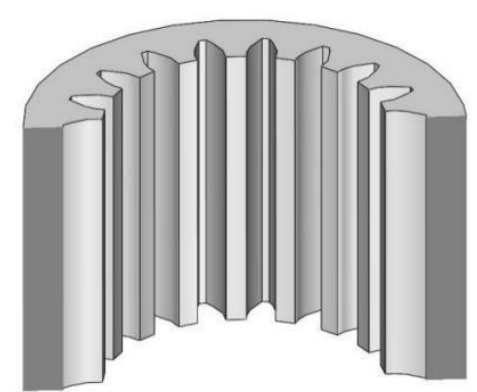

b) 3D section view

Figure 1 Geometric model of spur internal gear 


\subsection{Fixture design}

The purpose of this fixture is to guide the fluid to flow through the tooth surface of the internal gear and assist in the precision machining of the tooth surface of the gear. The fixture is mainly composed of guide device, clamp and fluid guide. The assembly drawing and explosion drawing are shown in Figure 2 and Figure 3. In the exploded view, 1 is the diversion device of the fixture, which connects the machine tool and the fixture through the thread at the entrance; 2 and 7 are hex bolts and hex nuts respectively, which connect the various parts of the fixture into a whole through connection and cooperation; 3 and 5 are soft sealing rings, which are used to prevent abrasive leakage due to excessive pressure during processing; 4 is the workpiece to be processed; 6 is the clamping body, its function is to cooperate with the guide device to fix the internal gear, and table a closed flow channel between the machine tool and the fixture; 8 is a drainage part, its function is to table a narrower flow path environment between the abrasive and the tooth surface of the internal gear through the cylinder at the upper end of the fluid, which is conducive to the finishing of the tooth surface.

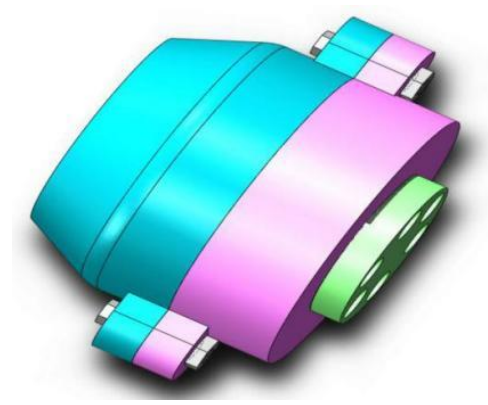

Figure 2 Fixture assembly drawing

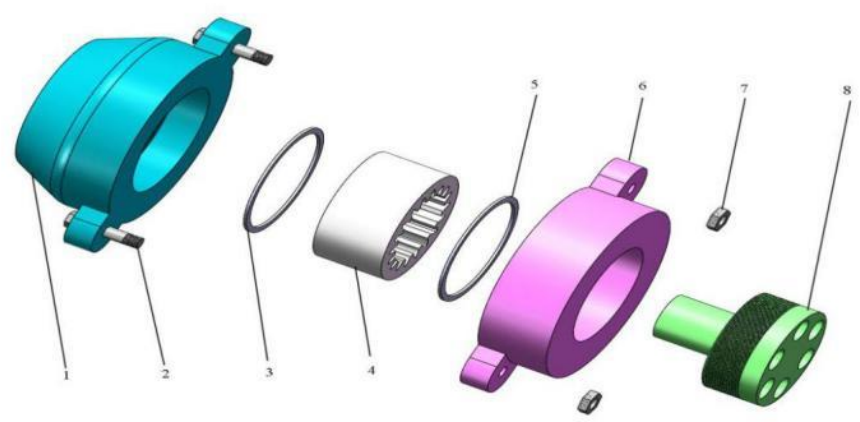

1-Diversion device; 2-Hex Bolts; 3-Sealing ring; 4-Internal gear; 5-Sealing ring; 6-

Folder specific; 7-Hex nuts; 8-Draw fluid

Figure 3 Exploded view of fixture 


\subsection{Numerical simulation analysis of spur internal gears}

Combined with the actual processing conditions of abrasive flow machining machine tool and the size of flow channel, set the inlet speed of abrasive flowing into the inner surface of workpiece $(30 \mathrm{~m} / \mathrm{s}, 40 \mathrm{~m} / \mathrm{s}, 50 \mathrm{~m} / \mathrm{s}$ and $60 \mathrm{~m} / \mathrm{s})$, the concentration of solid particles in abrasive $(10 \%, 20 \%, 30 \%$ and 40\%) and the particle size of abrasive solid particles (400 mesh, 600 mesh, 800 mesh and 1000 mesh), and the static pressure and The dynamic pressure, wall shear force and cogging velocity are numerically simulated and analyzed.

3.3.1 Numerical analysis of the entrance velocity on the machining of spur internal gears

The reason why the abrasive can flow through the workpiece surface to be machined is that the upper hydraulic cylinder of the abrasive flow machine tool can provide sufficient pressure for the abrasive to generate speed, so as to promote the abrasive to pass through the surface to be machined and finish the workpiece surface. Therefore, it is necessary to explore the influence of abrasive inlet velocity on machining effect

In this section, four reference speed values of $30 \mathrm{~m} / \mathrm{s}, 40 \mathrm{~m} / \mathrm{s}, 50 \mathrm{~m} / \mathrm{s}$ and $60 \mathrm{~m} / \mathrm{s}$ are selected. The abrasive concentration is $30 \%$ and the abrasive particle size is 600 mesh. The numerical simulation is carried out for the spur internal gear. The abrasive enters the flow channel from the left and flows out from the right.

1. Static pressure analysis of different inlet velocities

Select the above four different inlet velocity parameter values, and the other settings are consistent with the variables. The cloud diagram of static pressure distribution is given below, as shown in Figure 4. 

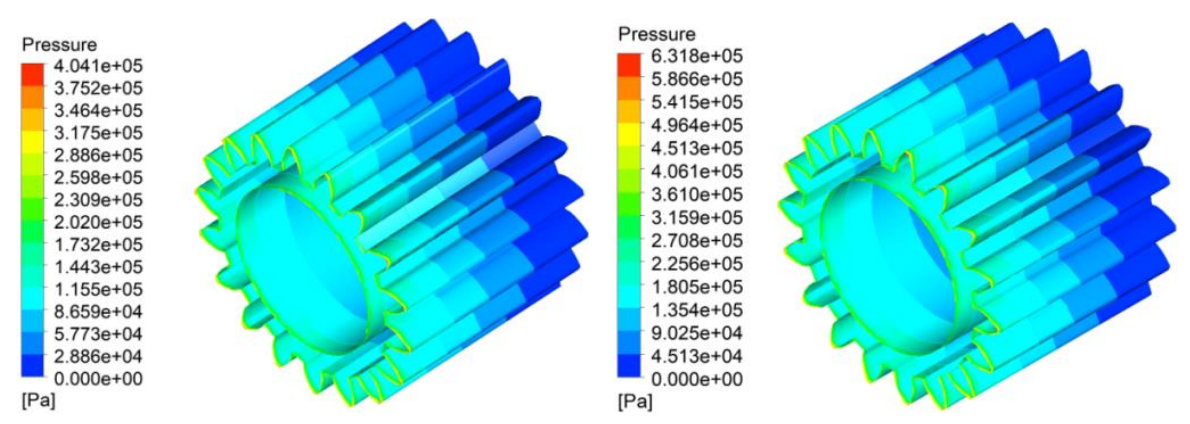

a) $\mathrm{v}=30 \mathrm{~m} / \mathrm{s}$

b) $v=40 \mathrm{~m} / \mathrm{s}$
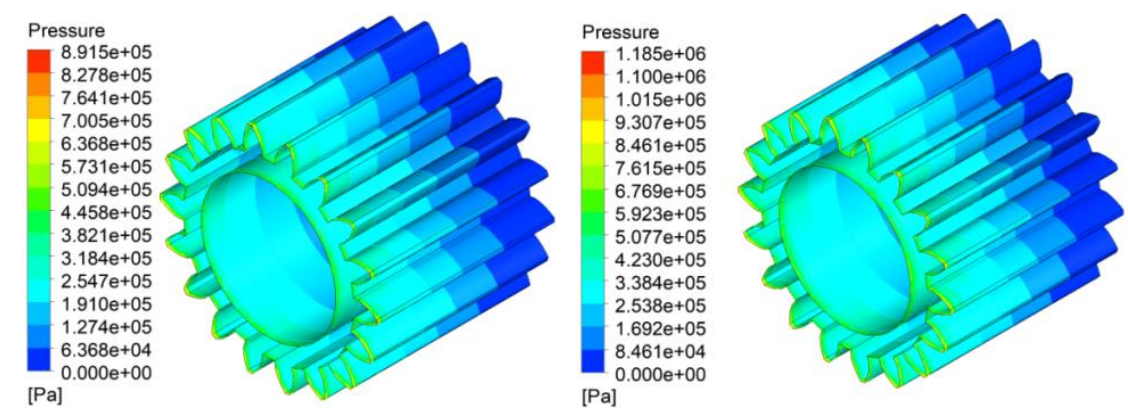

c) $\mathrm{v}=50 \mathrm{~m} / \mathrm{s}$

d) $v=60 \mathrm{~m} / \mathrm{s}$

Figure 4 Cloud diagram of static pressure distribution under different inlet velocities

Figure 4 is the static pressure cloud diagram obtained by using the large eddy simulation method under different inlet velocities. Obviously, under the conditions of four different entrance velocities, the static pressure cloud map of the spur internal gear wall shows the same changing characteristics, and the wall color changes from light to dark, showing a stepped distribution. This shows that the pressure at the inlet is the largest and the pressure at the outlet is the smallest, and the processing effect of the abrasive flow is gradually weakened.

2. Analysis of wall shearing force on different inlet velocities

When the abrasive flows through the workpiece surface, it is necessary to overcome the viscous resistance, resulting in shear force. The effect of abrasive flow machining depends on the influence of abrasive flow on the wall of the workpiece. The wall shear force can fully reflect the influence of abrasive flow machining on the wall of the workpiece. The wall shear stress nephogram under different inlet velocities is shown in Figure 5. 

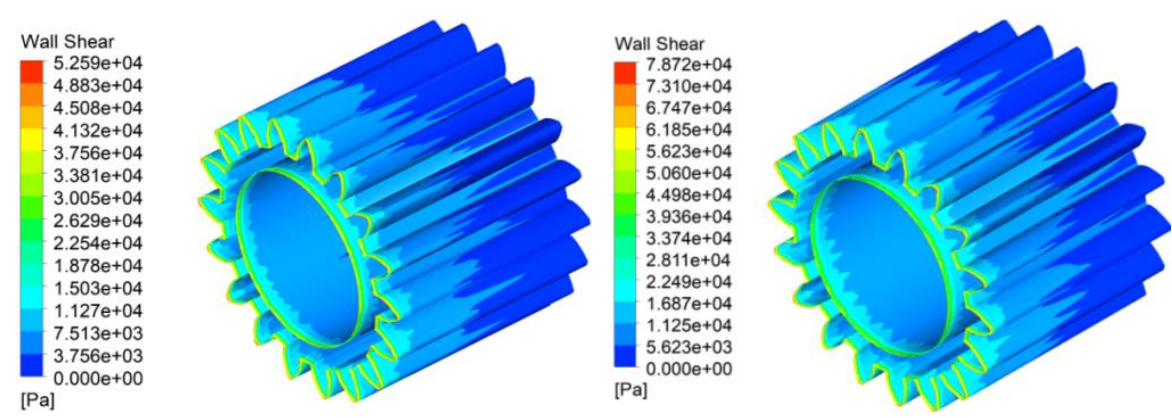

a) $v=30 \mathrm{~m} / \mathrm{s}$

b) $\mathrm{v}=40 \mathrm{~m} / \mathrm{s}$
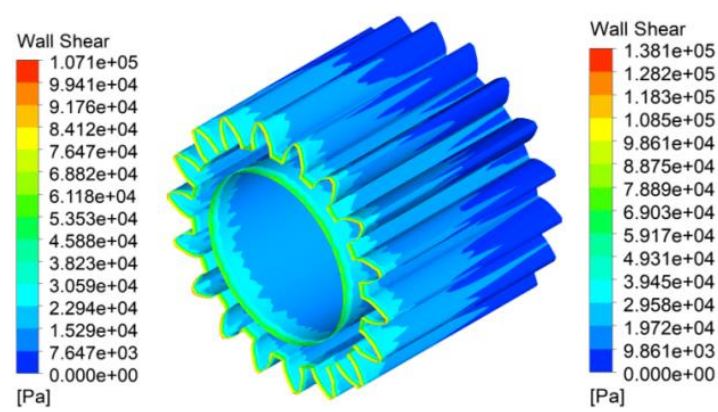

c) $\mathrm{v}=50 \mathrm{~m} / \mathrm{s}$

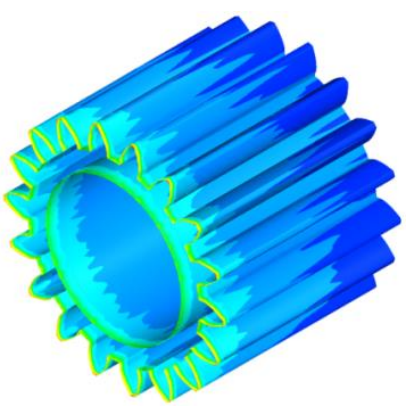

d) $v=60 \mathrm{~m} / \mathrm{s}$

Figure 5 Wall shear force cloud diagram under different inlet velocities

It can be seen from the figure 5 that the wall shearing force at the entrance is the largest. The number of abrasive particles in contact with the wall becomes smaller, the wall shearing force is also decreasing, and the processing effect is also change weakly. But as the entrance velocity increases, the wall shear force of the workpiece also increases; the light blue area in the middle increases, which shows that the increase in the entrance velocity can effectively improve the unitableity of processing. 


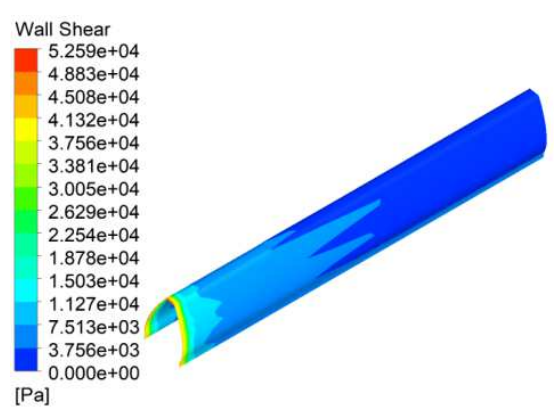

a) $v=30 \mathrm{~m} / \mathrm{s}$

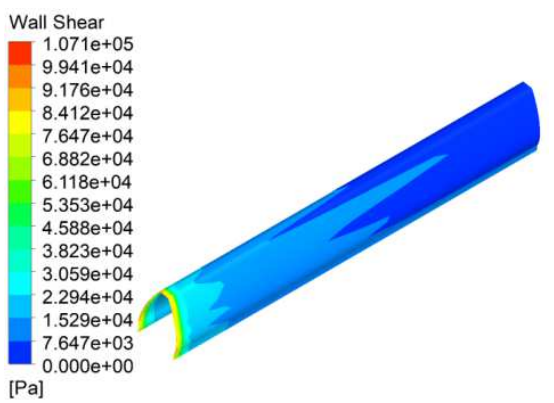

c) $\mathrm{v}=50 \mathrm{~m} / \mathrm{s}$

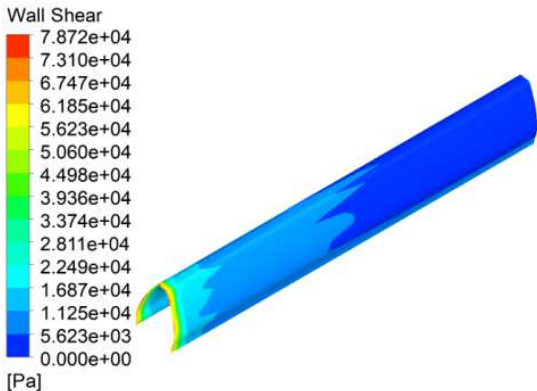

b) $v=40 \mathrm{~m} / \mathrm{s}$

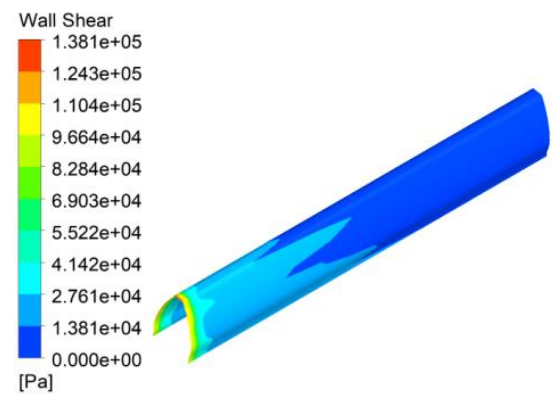

d) $v=60 \mathrm{~m} / \mathrm{s}$

Figure 6 Cloud diagram of cogging wall shear force under different inlet velocities

In order to visually observe the changes in the wall shear force of the spur internal gear, Figure 6 and Figure 7 are given. Figure 6 is the wall shear force cloud diagram of the tooth groove between two gear teeth, and Figure 7 is the wall shear force change curve at the top of the straight tooth internal gear tooth. Combining Figure 6 and Figure 7, it can be seen that at the same inlet velocity, the tooth surface wall shear force presents a trend of decreasing first and then stable. Under different inlet speeds, the wall shear force increases with the increase of the inlet speed, indicating that increasing the inlet speed is beneficial to the finishing of the tooth surface.

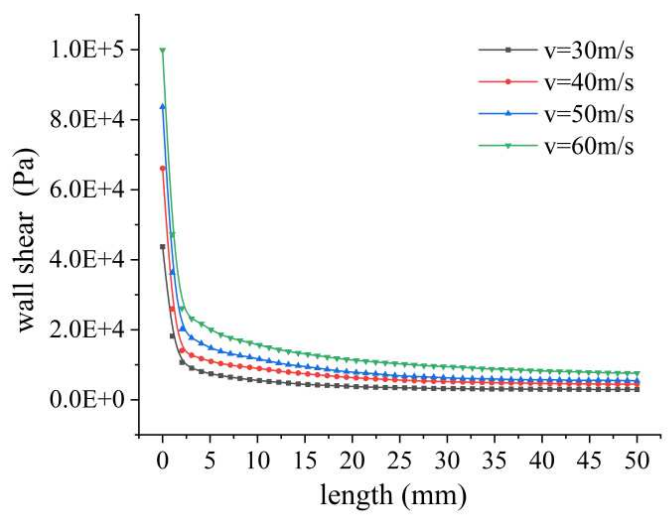

Figure 7 Change curve of tooth surface wall shear force under different inlet velocitys 3.3.2 Numerical Analysis of Abrasive Concentration on Straight-tooth Internal Gear Machining 
In the process of abrasive flow processing, if the concentration of abrasive is too high, the surface of the workpiece will be scratched and even the flow channel will be blocked; if the concentration of abrasive is too low, the processing effect of the surface of the workpiece is not obvious. Select the abrasive concentration value as the variable, set four groups of different abrasive concentrations of $10 \%, 20 \%, 30 \%$ and $40 \%$, the inlet velocity is $40 \mathrm{~m} / \mathrm{s}$, and the abrasive particle size is 600 mesh for numerical simulation.

1. Dynamic pressure analysis of abrasive concentration

Figure 8 is a cloud diagram of the axial dynamic pressure distribution of one of the tooth grooves under different abrasive concentrations. It can be seen from Figure 8 that under the same abrasive concentration, the upper wall of the tooth groove and the middle part of the tooth groove show different trends. The dynamic pressure at the middle position of the cogging shows a gradually increasing trend, the dynamic pressure at the inlet end is the smallest, and the dynamic pressure at the outlet end is the largest; The upper wall surface of the tooth groove shows the opposite trend to the middle part of the tooth groove. With the inflow of abrasive, the dynamic pressure on the upper wall surface becomes smaller and smaller, reaching a minimum at the outlet. Under different abrasive concentrations, with the increase of abrasive concentration, the dynamic pressure in the tooth groove gradually increases. When the abrasive concentration reaches $40 \%$, the value of dynamic pressure becomes significantly larger, the color of the dynamic pressure cloud image on the upper wall becomes lighter and becomes closer, and the distribution of the various colors of the cloud image in the middle of the tooth groove is more unitable, which shows that the appropriate increase Abrasive concentration can not only improve the surface finish of the wall surface, but also effectively improve the unitableity of the wall surface processing. 


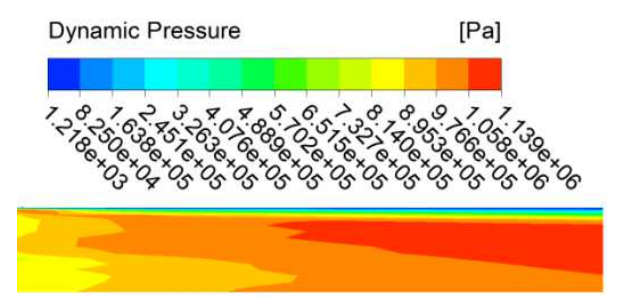

a) $10 \%$

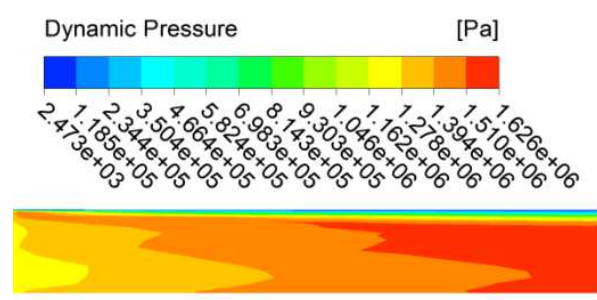

c) $30 \%$

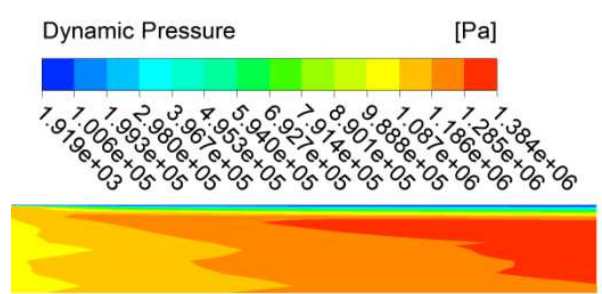

b) $20 \%$

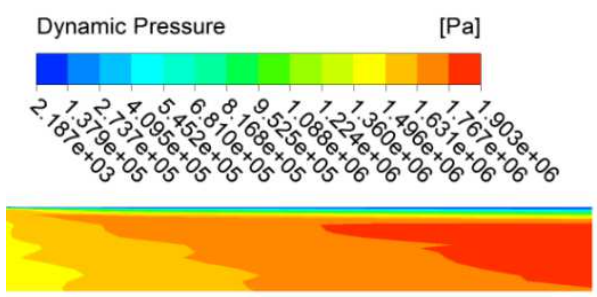

d) $40 \%$

Figure 8 Cloud diagram of dynamic axial pressure distribution of tooth groove under different abrasive concentration

2. Wall shear force analysis of different abrasive concentrations

Figure 9 shows the wall shear force cloud diagram of the spur internal gear under different abrasive concentrations. The abrasive particles enter the flow channel from the left and flow out from the right. It can be seen from Figure 9 that as the concentration of abrasive increases, the overall wall shear force of the spur internal gear can be effectively increased.

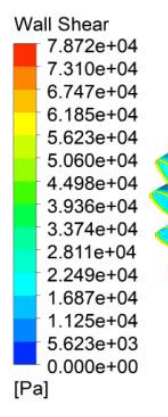

a) $10 \%$

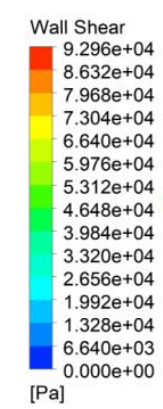

c) $30 \%$

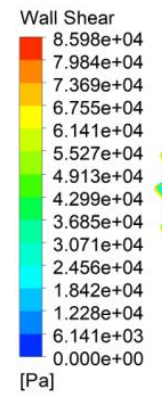

$[\mathrm{Pa}]$
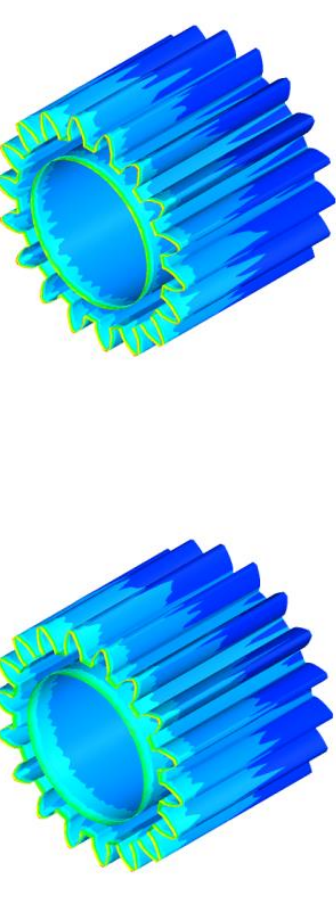
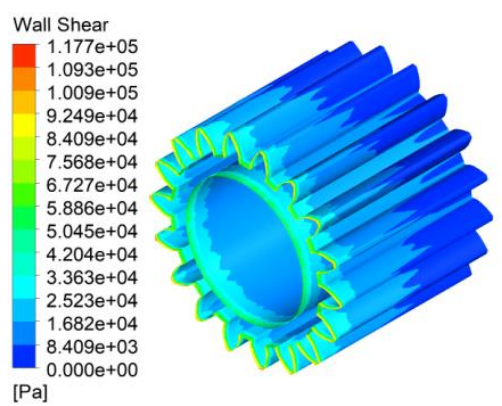

d) $40 \%$

Figure 9 Clouds of wall shear force under different abrasive concentrations 
In order to more intuitively analyze the influence of different concentrations on the wall shearing force of the tooth tip, tooth root, and tooth surface, a tooth slot in the spur internal gear is extracted, as shown in Figure 10.

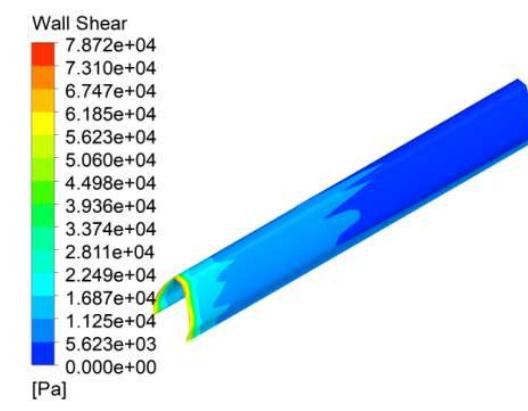

a) $10 \%$

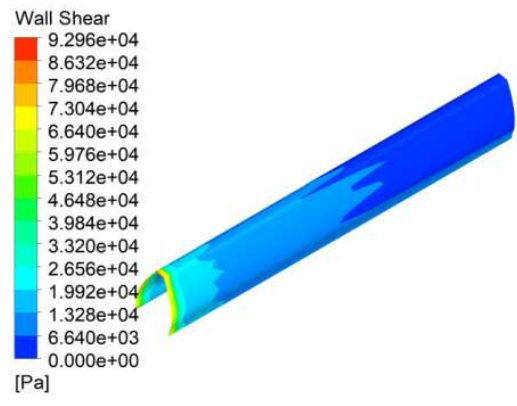

c) $30 \%$

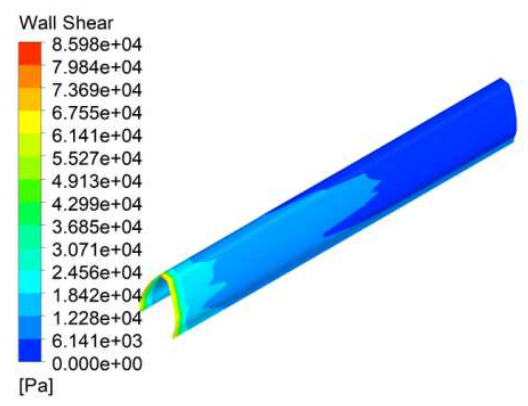

b) $20 \%$

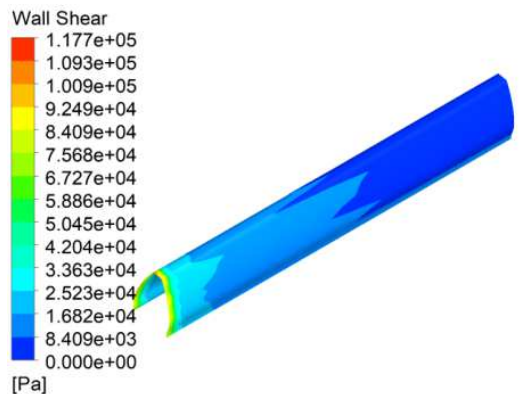

d) $40 \%$

Figure 10 Clouds of shear force on the tooth groove wall under different abrasive concentrations

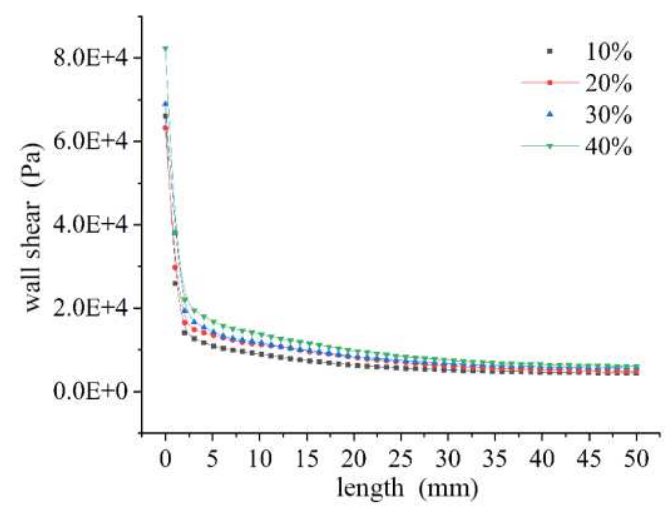

Figure 11 Change curve of tooth surface wall shear force under different abrasive concentration

When the abrasive concentration is constant, the shear force on the tooth surface generally decreases first and then remains stable. The wall shearing force of the tooth surface at the entrance is the largest, and the wall shearing force of the $0 \sim 4 \mathrm{~mm}$ section has the fastest decline. The wall shearing force after the tooth surface $4 \mathrm{~mm}$ decreases slowly until the latter half remains unchanged. It shows that the surface quality at the entrance of the tooth surface is the best, and the machining 
of the middle and rear sections is more unitable. When using abrasives with concentrations of $10 \%$, $20 \%$, and $30 \%$, the maximum wall shearing force at the entrance is not much different, and the variation range of the wall shearing force of the tooth surface from 0 to $4 \mathrm{~mm}$ is basically the same. The $20 \%$ and $30 \%$ change curves even coincide after $12 \mathrm{~mm}$, which shows that the effect of the first three concentrations of abrasives in processing the tooth surface is very close; When the abrasive with a concentration of $40 \%$ is used for processing, although the wall shearing force at the entrance increases significantly, the subsequent wall shearing force is only slightly higher than the wall shearing force of the first three concentrations. In general, the relationship between the four abrasives with different concentrations in the numerical simulation on the tooth surface machining effect is $40 \%>30 \% \approx 20 \%>10 \%$.

3.3.3 Numerical analysis of abrasive particle size on the machining of spur internal gears

In abrasive flow machining, in addition to the inlet speed and abrasive concentration, abrasive particle size is also one of the important factors affecting the machining effect. Therefore, this section will numerically analyze the effect of abrasive particle size on the machining of spur internal gear. Set the inlet speed as $40 \mathrm{~m} / \mathrm{s}$ and the abrasive concentration as $10 \%$. Take the abrasive particle sizes of 400 mesh $(38 \mu \mathrm{m}), 600$ mesh $(25 \mu \mathrm{m}), 800$ mesh $(18 \mu \mathrm{m})$ and 1000 mesh $(15 \mu \mathrm{m})$ for numerical analysis.

1. Velocity vector analysis of different abrasive particle size

The above four kinds of abrasive grains are used to numerically simulate the spur internal gear, and the velocity vector cloud diagram in the tooth groove is obtained, as shown in Figure 12.

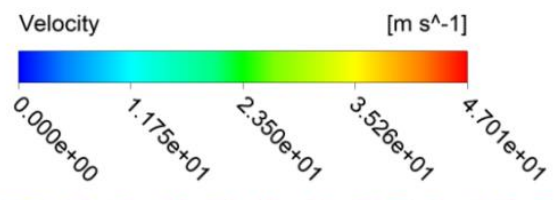

a) 400 mesh

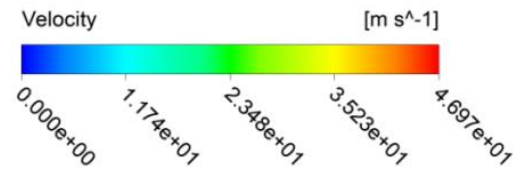

c) 800 mesh

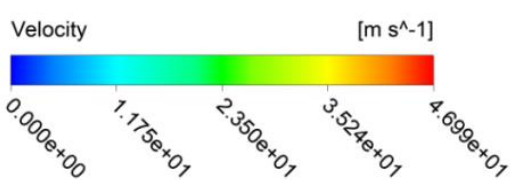

b) 600 mesh

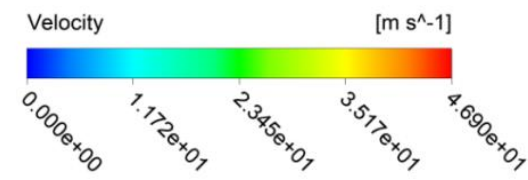

d) 1000 mesh

Figure 12 The velocity vector cloud diagram of the tooth groove axial cross section under 


\section{different abrasive particle sizes}

The velocity vector cloud diagram mainly reflects the changes in the direction of the abrasive particle flow trajectory and the size of the abrasive particle velocity, which can be seen from Figure 12:(1) when the workpiece is processed with abrasives of the same particle size, the velocity of the abrasive particles at the entrance changes from red to gold and then to green, indicating that the abrasive enters the flow channel after friction with the wall, and the velocity drops rapidly; The direction of the abrasive particles at the entrance changes from horizontal to right to diagonally downward, indicating that the abrasive particles enter the flow channel and collide with the wall surface and have a tendency to rebound to the middle of the flow channel. (2) When the abrasive grain size is different, the larger the number of abrasive grains, the finer the abrasive grains, and the smaller the mass of a single abrasive grain, the smaller the energy carried, which shows that the velocity is lower and the processing effect is slightly insufficient.

In order to show the velocity difference of different abrasive particle sizes more intuitively, the maximum and minimum data tables for different abrasive particle sizes at the outlet of the tooth groove are listed, as shown in table 2 .

Table 2 Numerical table of velocity at different abrasive particle size at the outlet of the tooth

\begin{tabular}{ccc} 
& \multicolumn{2}{c}{ groove } \\
\hline \multirow{2}{*}{$\begin{array}{c}\text { Abrasive particle } \\
\text { size }(\text { mesh })\end{array}$} & \multicolumn{2}{c}{ velocity $(\mathrm{m} / \mathrm{s})$} \\
\cline { 2 - 3 } 400 & 47.01 & Min \\
600 & 46.99 & 4.683 \\
800 & 46.97 & 4.667 \\
1000 & 46.90 & 4.649 \\
\end{tabular}

According to table 2, it can be seen that with the increase of abrasive particle size, the maximum and minimum velocities both show a slight decrease trend. Abrasive velocity and processing effect can be said to have a proportional relationship within a certain range. The higher the velocity, the more severe the abrasive friction on the surface of the workpiece, and the better the processing effect. It can also be found from table 2 that the difference in the decrease in the maximum velocity between the abrasive particle sizes is much smaller than the decrease in the minimum velocity. That is to say, the larger the abrasive particle size, the smaller the difference between the maximum and minimum abrasive velocity, and the more unitable the processing. From the processing effect, the order of selection should be: 400 mesh>600 mesh>800 mesh>1000 mesh; 
From the point of view of the unitableity effect of processing, the order of selection should be: 1000 mesh>800 mesh>600 mesh>400 mesh.

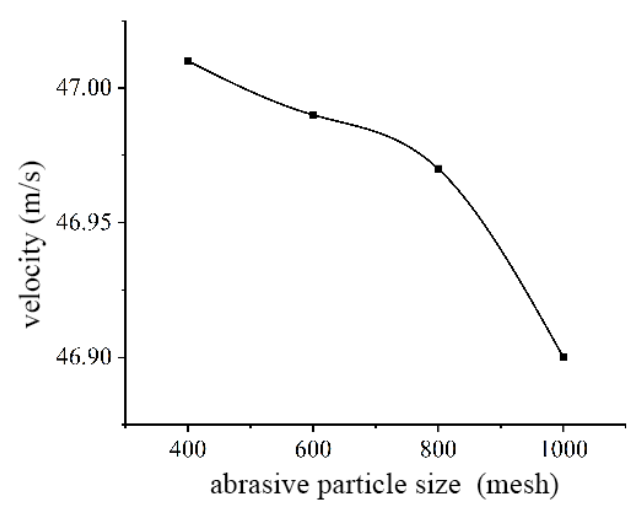

a) Maximum velocity

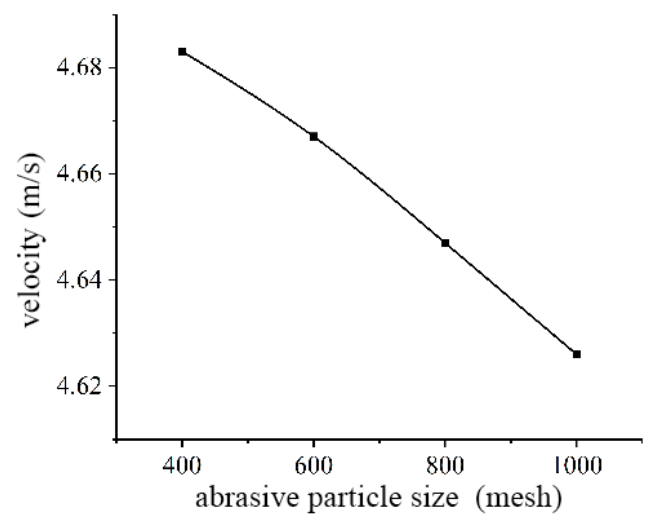

b) Minimum velocity

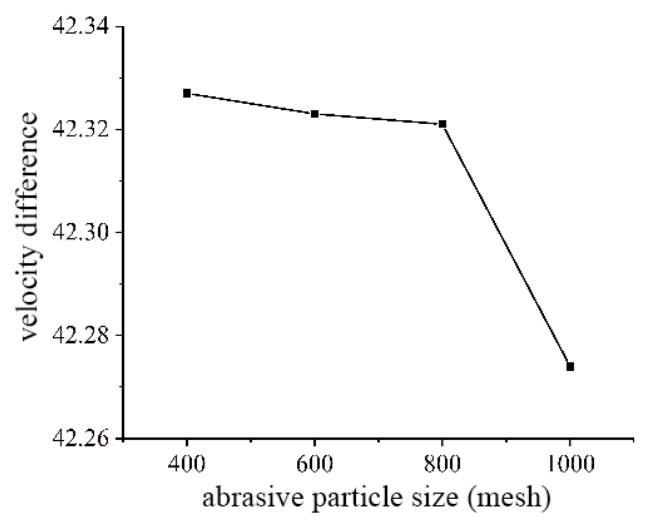

c) Difference in velocity

Figure 13 velocity comparison curve of different abrasive grain sizes at the outlet of the tooth groove

Draw the maximum velocity comparison curve in Figure 13. It can be seen from Figure 13 that with the increase of the abrasive particle size, the maximum and minimum abrasive velocity at the outlet of the tooth groove show a decreasing trend, and the difference between the maximum velocity and the minimum velocity under each abrasive particle size is also Decreasing. Therefore, when the abrasive particle size is selected to be 400 mesh, the processing effect of the workpiece wall is the best; when the abrasive concentration is selected to be 1000 mesh, the unitable processing effect of the workpiece wall is the best.

2. Wall shear force analysis of different abrasive particle size

Figure 14 is the wall shear force cloud diagram of the same tooth groove with different abrasive particle sizes. It can be seen from the figure that with the increase of the abrasive mesh, although 
the wall shearing force of the tooth groove gradually decreases, the unitableity of the tooth groove is gradually getting better.

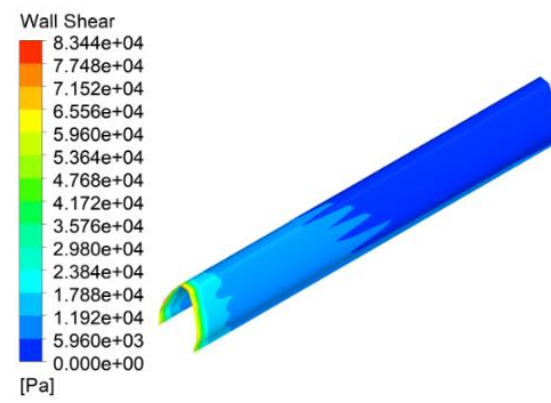

a) $400 \mathrm{mesh}$

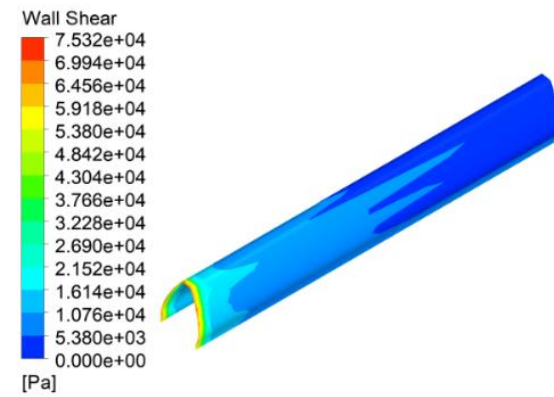

c) 800 mesh

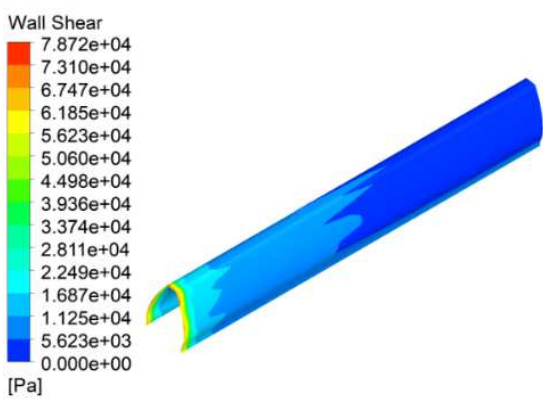

b) 600 mesh

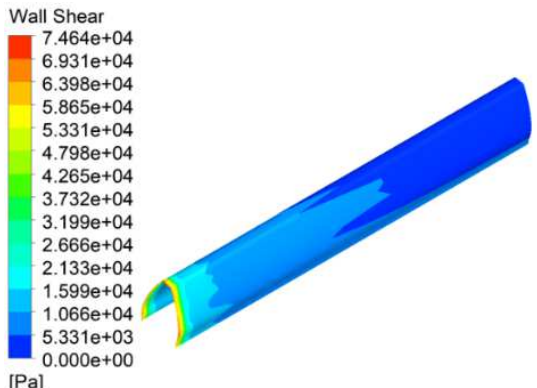

d) 1000 mesh

Figure 14 Clouds of shear force on the tooth groove wall under different abrasive particle sizes

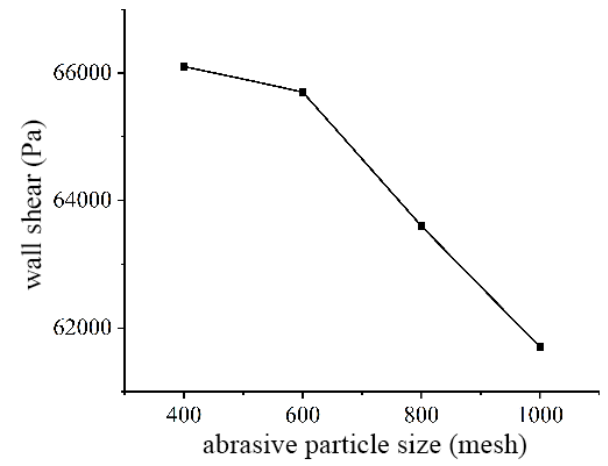

a) Maximum wall shear force

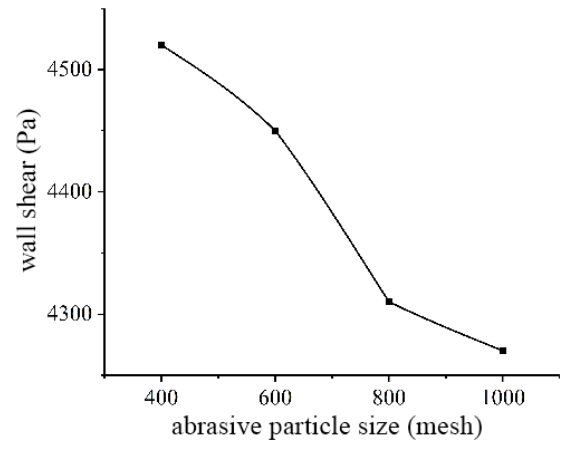

b) Minimum wall shear force

Figure 15 Comparison curve of tooth surface wall shear force under different particle diameters

Figure 15 is the comparison curve of the maximum wall shear force and the minimum wall shear force of the tooth surface under different abrasive particle sizes. The effect of different abrasive particle sizes on the tooth surface processing is slightly different, and the 400 mesh abrasive processing effect is better. 


\section{Experimental research on abrasive flow machining of spur internal gears}

Taking the straight internal gear as the test object, combined with numerical simulation analysis, the abrasive flow machining test of straight internal gear is carried out. Through detection and analysis, it provides technical guidance for abrasive flow machining technology

\subsection{Preparation for abrasive flow machining test}

\subsubsection{Selection of test objects}

In order to more accurately predict the actual abrasive flow production and processing, the straight internal gear is used as the research object for numerical simulation analysis and experimental processing respectively. The specific physical drawing of the workpiece is shown in Figure 16.

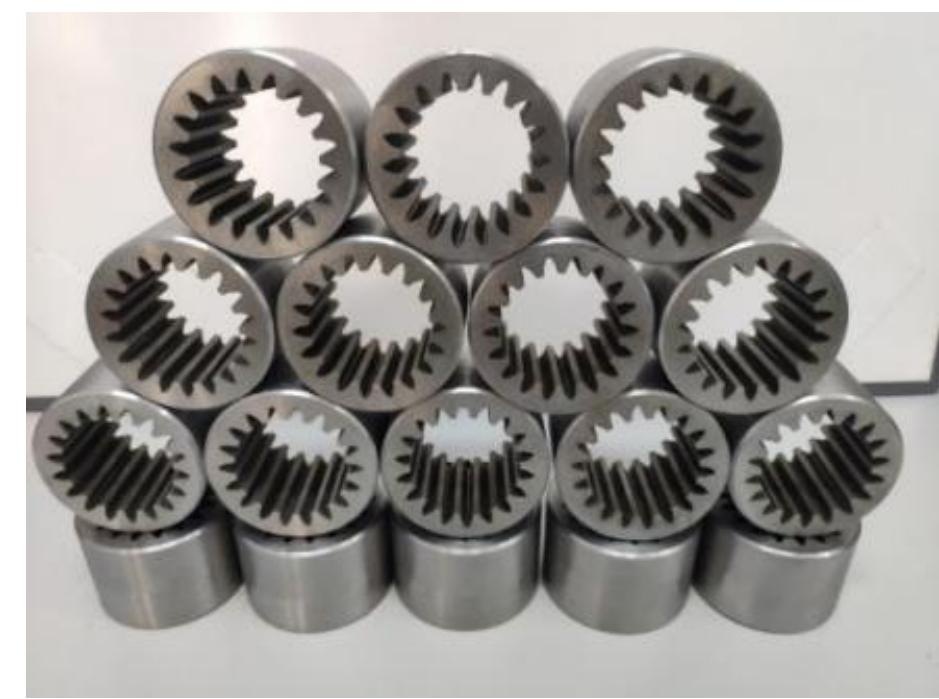

Figure 16 Physical image of spur internal gear

\subsubsection{Design of the test plan}

The purpose of the test is to study the effects of four factors (inlet speed, abrasive concentration, abrasive particle size and machining times) on abrasive flow machining of spur internal gears. Combined with numerical simulation analysis, the factors-level table and orthogonal test table of factors are designed, as shown in Table 3 and table 4 respectively. 
Table 3 Test factors-level table

\begin{tabular}{|c|c|c|c|c|}
\hline factor & A & B & $\mathrm{C}$ & $\mathrm{D}$ \\
\hline Level & $\begin{array}{l}\text { Entrance velocity } \\
\qquad(\mathrm{m} / \mathrm{s})\end{array}$ & $\begin{array}{c}\text { Abrasive } \\
\text { concentration } \\
(\%)\end{array}$ & $\begin{array}{c}\text { Abrasive particle } \\
\text { size } \\
(\text { mesh })\end{array}$ & Processing times \\
\hline 1 & 30 & 10 & 400 & 10 \\
\hline 2 & 40 & 20 & 600 & 20 \\
\hline 3 & 50 & 30 & 800 & 30 \\
\hline 4 & 60 & 40 & 1000 & 40 \\
\hline
\end{tabular}

Table 4 orthogonal table

\begin{tabular}{ccccc}
\hline & \multicolumn{4}{c}{ Experimental conditions } \\
Test & velocity & concentration & Particle size \\
number & $(\mathrm{m} / \mathrm{s})$ & $(\%)$ & Times \\
& & & & \\
\hline 1 & 30 & 10 & 400 & 10 \\
2 & 30 & 20 & 600 & 20 \\
3 & 30 & 30 & 800 & 30 \\
4 & 30 & 40 & 1000 & 40 \\
5 & 40 & 10 & 600 & 30 \\
6 & 40 & 20 & 400 & 40 \\
7 & 40 & 30 & 1000 & 10 \\
8 & 40 & 40 & 800 & 20 \\
9 & 50 & 10 & 800 & 40 \\
10 & 50 & 20 & 1000 & 30 \\
11 & 50 & 30 & 400 & 20 \\
12 & 50 & 40 & 600 & 10 \\
13 & 60 & 10 & 1000 & 20 \\
14 & 60 & 20 & 800 & 10 \\
15 & 60 & 30 & 600 & 40 \\
16 & 60 & 40 & 400 & 30 \\
\hline
\end{tabular}

\subsection{Detection of abrasive flow processing results}

\subsubsection{Detection of the surface topography of spur internal gears}

In order to visually observe the surface morphology of the tooth surface in the tooth groove, a scanning electron microscope is used for inspection. Samples are taken every three times from the original 00\# to the test piece 16\#. The scanning results are shown in Figure 4.2. 


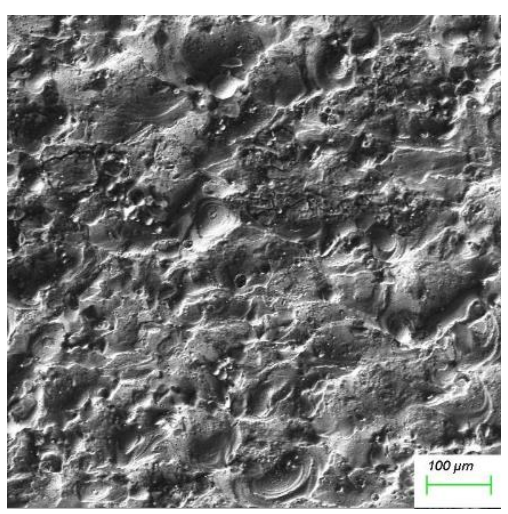

a) $00 \#$

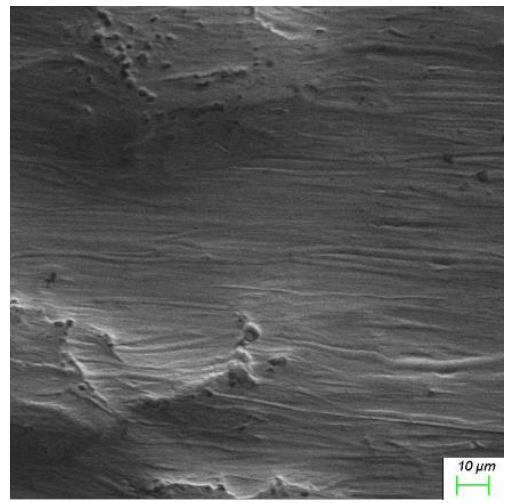

c) $08 \#$

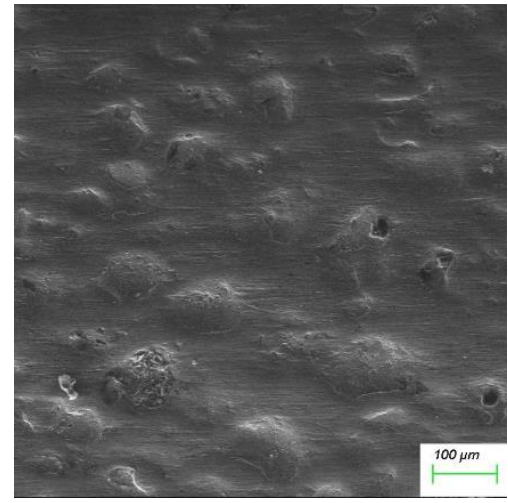

b) $04 \#$

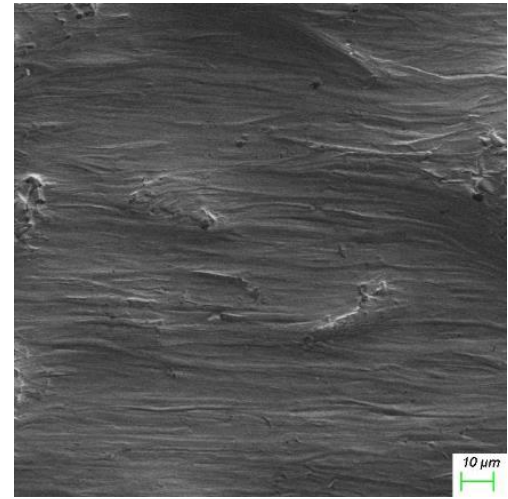

d) $12 \#$

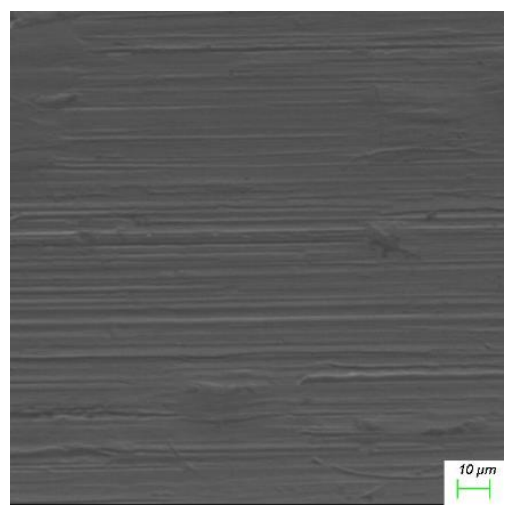

e) $16 \#$

Figure 17 Tooth surface profile of spur internal gear

It can be seen from Figure 17 that there are obvious spot-like protrusions and pits of various shapes on the tooth surface of the original. The surface is not only uneven, but also has poor gloss. After the solid-liquid two-phase abrasive flow processing, the quality of the tooth surface is significantly improved. With the change of processing parameters, the protrusions on the inner surface of the test piece become less and less, and the surface becomes more and more flat and smooth. When the electron microscope is magnified 500 times, the fine scratches left on the inner surface of the test piece after abrasive processing can be observed. These scratches are lines 
generated by abrasive flow processing.

\subsubsection{Surface roughness detection of spur internal gears}

The surface roughness of the tooth surface of the tooth groove is measured by the Marl LD120 surface roughness profile measuring instrument, and the test results are drawn in a table, as shown in table 5 .

Table 5 Straight tooth internal gear tooth surface roughness numerical table

\begin{tabular}{cccccccccc}
\hline number & $00 \#$ & $01 \#$ & $02 \#$ & $03 \#$ & $04 \#$ & $05 \#$ & $06 \#$ & $07 \#$ & $08 \#$ \\
\hline Surface roughness & 3.918 & 2.423 & 2.305 & 2.193 & 1.868 & 1.450 & 1.280 & 1.611 & 1.300 \\
(um) & & & & & & & & & \\
number & $09 \#$ & $10 \#$ & $11 \#$ & $12 \#$ & $13 \#$ & $14 \#$ & $15 \#$ & $16 \#$ & \\
Surface roughness & 0.873 & 1.051 & 0.894 & 0.824 & 0.655 & 0.671 & 0.426 & 0.380 & \\
$($ um $)$ & & & & & & & & & \\
\hline
\end{tabular}

In order to see the changes of the surface roughness values of different tooth surfaces more intuitively and clearly, draw a line graph of the tooth surface roughness of the spur internal gear according to table 5, as shown in Figure 18.

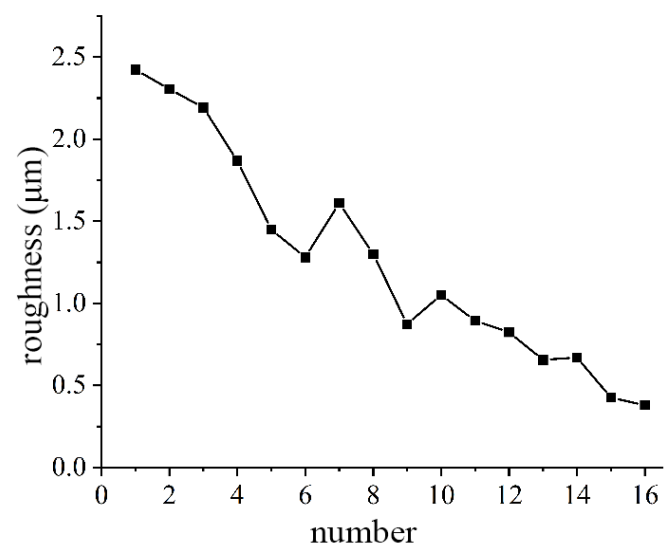

Figure 18 Line graph of tooth surface roughness change of spur internal gear

Combining Figure 18 and Table 5, it can be found that the tooth surface roughness of the spur internal gear without solid-liquid two-phase abrasive flow processing reaches $3.918 \mu \mathrm{m}$. After the processing is completed, the minimum value of the spur internal gear tooth surface roughness is one order of magnitude smaller, reaching $0.380 \mu \mathrm{m}$, which effectively improves the quality of the spur internal gear tooth surface, reduces the surface roughness, and improves the working pertableance of the spur internal gear.

\subsection{Analysis of processing results}

\subsubsection{Range analysis of orthogonal test}

According to the designed orthogonal test table and the corresponding roughness value, it is 
summarized and calculated, and the orthogonal range analysis table shown in table 6 is obtained.

Table 6 Orthogonal range analysis table

\begin{tabular}{|c|c|c|c|c|c|}
\hline \multirow[b]{2}{*}{ Test number } & \multicolumn{4}{|c|}{ Experimental conditions } & \multirow{2}{*}{$\begin{array}{l}\text { Test index } \\
\text { Roughness } \\
\quad(\mu \mathrm{m})\end{array}$} \\
\hline & $\begin{array}{c}\text { Entrance velocity } \\
\qquad(\mathrm{m} / \mathrm{s}) \mathrm{A}\end{array}$ & $\begin{array}{c}\text { Abrasive } \\
\text { concentration } \\
(\%) \\
\text { B }\end{array}$ & $\begin{array}{c}\text { Abrasive particle size } \\
\qquad \begin{array}{c}\text { (mesh }) \\
\text { C }\end{array}\end{array}$ & $\begin{array}{c}\text { Times } \\
\text { D }\end{array}$ & \\
\hline 1 & 30 & 10 & 400 & 10 & 2.423 \\
\hline 2 & 30 & 20 & 600 & 20 & 2.305 \\
\hline 3 & 30 & 30 & 800 & 30 & 2.193 \\
\hline 4 & 30 & 40 & 1000 & 40 & 1.868 \\
\hline 5 & 40 & 10 & 600 & 30 & 1.450 \\
\hline 6 & 40 & 20 & 400 & 40 & 1.280 \\
\hline 7 & 40 & 30 & 1000 & 10 & 1.611 \\
\hline 8 & 40 & 40 & 800 & 20 & 1.300 \\
\hline 9 & 50 & 10 & 800 & 40 & 0.873 \\
\hline 10 & 50 & 20 & 1000 & 30 & 1.051 \\
\hline 11 & 50 & 30 & 400 & 20 & 0.894 \\
\hline 12 & 50 & 40 & 600 & 10 & 0.824 \\
\hline 13 & 60 & 10 & 1000 & 20 & 0.655 \\
\hline 14 & 60 & 20 & 800 & 10 & 0.671 \\
\hline 15 & 60 & 30 & 600 & 40 & 0.426 \\
\hline 16 & 60 & 40 & 400 & 30 & 0.380 \\
\hline $\mathrm{K}_{\mathrm{j} 1}$ & 8.789 & 5.401 & 4.977 & 5.529 & \\
\hline $\mathrm{K}_{\mathrm{j} 2}$ & 5.641 & 5.307 & 5.005 & 5.154 & \\
\hline $\mathrm{K}_{\mathrm{j} 3}$ & 3.642 & 5.124 & 5.037 & 5.074 & \\
\hline $\mathrm{K}_{\mathrm{j} 4}$ & 2.132 & 3.954 & 5.185 & 4.447 & \\
\hline $\mathrm{k}_{\mathrm{j} 1}$ & 2.1972 & 1.3503 & 1.2443 & 1.3822 & \\
\hline $\mathrm{k}_{\mathrm{j} 2}$ & 1.4103 & 1.3268 & 1.2512 & 1.2885 & $\sum=?$ \\
\hline $\mathrm{k}_{\mathrm{j} 3}$ & 0.9105 & 1.2810 & 1.2593 & 1.2685 & \\
\hline $\mathrm{k}_{\mathrm{j} 4}$ & 0.5330 & 1.0930 & 1.2963 & 1.1118 & \\
\hline $\mathrm{R}_{\mathrm{i}}$ & 1.6643 & 0.2573 & 0.0520 & 0.2705 & \\
\hline $\begin{array}{c}\text { Excellent } \\
\text { level }\end{array}$ & 60 & 40 & 400 & 40 & \\
\hline Rank & 1 & 3 & 4 & 2 & \\
\hline
\end{tabular}

In table 6 , the tooth surface roughness is used as the test index, and the influence of four factors on the effect of processing the tooth surface of the straight tooth internal gear is analyzed. It can be seen from Table 6 that the tooth surface roughness generally shows a decreasing law, the highest is the tooth surface roughness of test piece $01 \#$ is $2.423 \mu \mathrm{m}$; the lowest is the tooth surface roughness of test piece $16 \#$ is $0.380 \mu \mathrm{m}$. In order to analyze the influence of different factors on the processing effect, it is necessary to calculate and compare the 16 sets of test data in order to find the more 
important processing factors and the best level value of each factor. The "Kj" in the table is the sum of the test data at the same level in the corresponding column. The larger the $\mathrm{Kj}$ value, the greater the roughness value of the tooth surface at this level. Take the inlet velocity as an example: the $\mathrm{Kj}$ values corresponding to the inlet velocity of $30 \mathrm{~m} / \mathrm{s}, 40 \mathrm{~m} / \mathrm{s}, 50 \mathrm{~m} / \mathrm{s}$, and $60 \mathrm{~m} / \mathrm{s}$ are $8.789,5.641$, $3.642,2.132$ respectively, namely $\mathrm{K} 1>\mathrm{K} 2>\mathrm{K} 3>\mathrm{K} 4$, The smaller the tooth surface roughness, the better the working pertableance. It can be judged that when the inlet velocity is $60 \mathrm{~m} / \mathrm{s}$, a better surface quality can be obtained. Similarly, the optimal levels of the other three factors are: $40 \%$, 400 mesh, and 40 times. The "Rj" in the table is the range of the factor in the corresponding column, the range is large, and it has a large impact on the test results, and is the main factor; the range is small, and the impact on the test results is small, and it is a secondary factor. The $\mathrm{R}$ values corresponding to the inlet velocity, abrasive concentration, abrasive particle size, and processing times are $1.6643,0.2573,0.0520,0.2705$, respectively. It can be seen that the inlet velocity has the greatest influence on the processing effect, and the abrasive particle size has the smallest effect on the processing effect.

In order to show the influence of different factors and levels on the test processing results more intuitively and clearly, the relationship between different factors and test indicators is drawn, as shown in Figure 19.

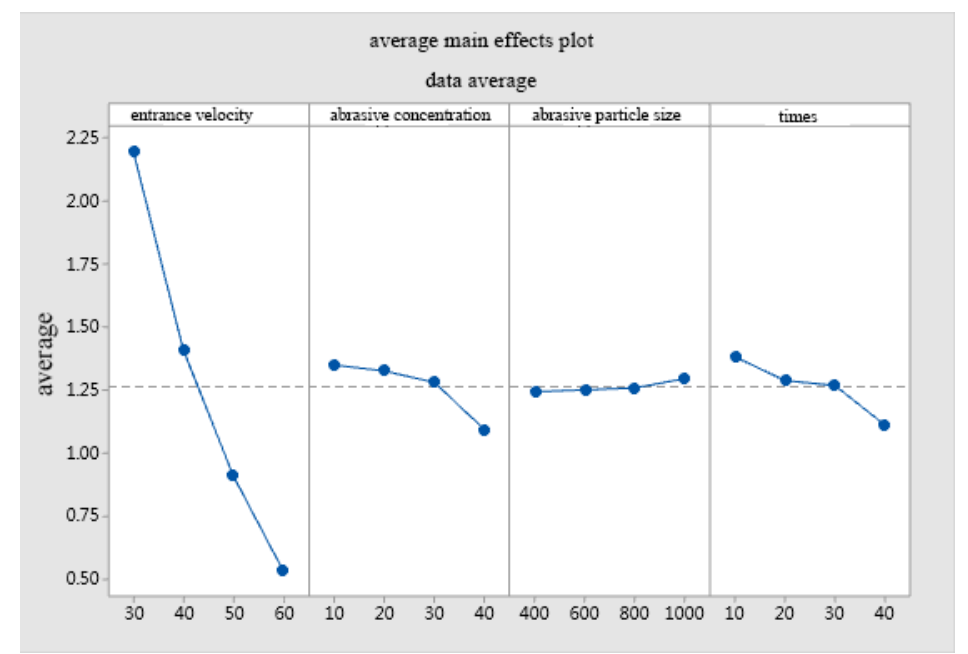

Figure 19 Relationship between different factors and test indicators

It can be seen from Figure 19 that different factors have different effects on the test indicators as the level changes. The slope of the broken line in the figure indicates the degree of influence of the factor on the test index. The larger the slope, the more significant the effect; the lower the mean value, the better the processing effect at this level. Therefore, the optimal combination of processing 
parameters is: the inlet velocity is $60 \mathrm{~m} / \mathrm{s}$, the abrasive concentration is $40 \%$, the abrasive particle size is 400 mesh, and the number of processing is 40 times.

\subsubsection{Analysis of Variance in Orthogonal Test}

The optimal conditions have been obtained by the range analysis method of orthogonal experiment. This method only needs to do a small amount of calculation and analysis on the obtained test data, but the accuracy of the analysis cannot be grasped. The analysis of variance method is a mathematical method that decomposes the sum of squares of the total variance according to various factors that give the dispersion degree, and then pertables statistics and testing. It can well make up for the deficiencies of the range analysis method. The analysis of the variance table shown in table 7 can be obtained by using the analysis of variance method.

Table 7 Analysis of Variance table

\begin{tabular}{|c|c|c|c|c|c|c|}
\hline & $\begin{array}{l}\text { Degree of } \\
\text { freedom }\end{array}$ & Adj SS & & Adj MS & F value & $P$ value \\
\hline $\begin{array}{l}\text { Entrance } \\
\text { velocity }\end{array}$ & 3 & 6.20665 & & 2.06888 & 334.82 & 0.000 \\
\hline $\begin{array}{c}\text { Abrasive } \\
\text { concentration }\end{array}$ & 3 & 0.15111 & & 0.05037 & 8.15 & 0.059 \\
\hline $\begin{array}{c}\text { Abrasive } \\
\text { particle size }\end{array}$ & 3 & 0.00644 & & 0.00215 & 0.35 & 0.796 \\
\hline $\begin{array}{l}\text { Processing } \\
\text { times }\end{array}$ & 3 & 0.16360 & & 0.05453 & 8.83 & 0.053 \\
\hline deviation & 3 & 0.01854 & & 0.00618 & & \\
\hline \multirow[t]{2}{*}{ total } & 15 & 6.54633 & & & & \\
\hline & $S=0.0786077$ & $\mathrm{R}-\mathrm{sq}=99.72 \%$ & R-sq & (Adjustment) & $=98.58 \%$ & \\
\hline
\end{tabular}

According to the variance detection method, when the $\mathrm{P}$ value is less than 0.05 , it means that this factor has a significant impact on the test results. It can be seen from Table 3.5 that the $\mathrm{P}$ value of the entrance velocity is 0 , indicating that the influence of the entrance velocity on the experimental results is significant; The $\mathrm{P}$ values of processing times and abrasive concentration are 0.053 and 0.059 , respectively, indicating that the processing times and abrasive concentration have a significant influence on the test results, and the processing times have a greater influence; The $\mathrm{P}$ value of the abrasive particle size is 0.796 , indicating that the abrasive particle size has no significant influence on the test results. Combining the above analysis and the data in the table, it can be seen that the order of the influence degree of the four factors on the experimental processing results is: inlet velocity>processing times>abrasive concentration>abrasive particle size, it is consistent with 
the conclusion obtained by the range analysis, which also verifies the correctness of the range analysis.

\subsection{Analysis of Optimal Parameters for Machining Straight Internal}

\section{Gears}

After the above orthogonal test analysis, the optimal combination of processing parameters under the four factors of inlet velocity, abrasive concentration, abrasive particle size and processing times is: inlet velocity of $60 \mathrm{~m} / \mathrm{s}$, abrasive concentration of $40 \%$, abrasive particle size It is $400 \mathrm{mesh}$, and the number of processing is 40 times. But there is no combination of this set of parameters in the orthogonal test table, so it is necessary to add a set of tests. The operation of the test and the method of testing are the same as before, and the testing diagrams are shown in Figures 20 to 21 .

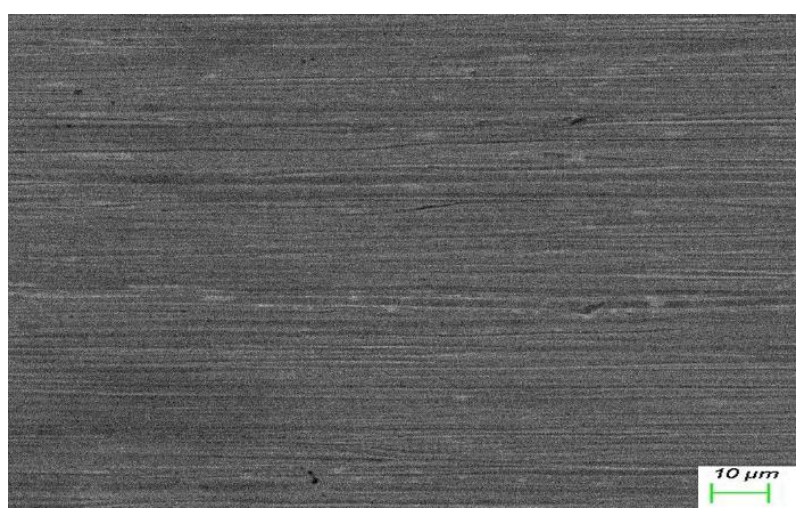

Figure 20 Scanning electron microscope tooth surface inspection diagram

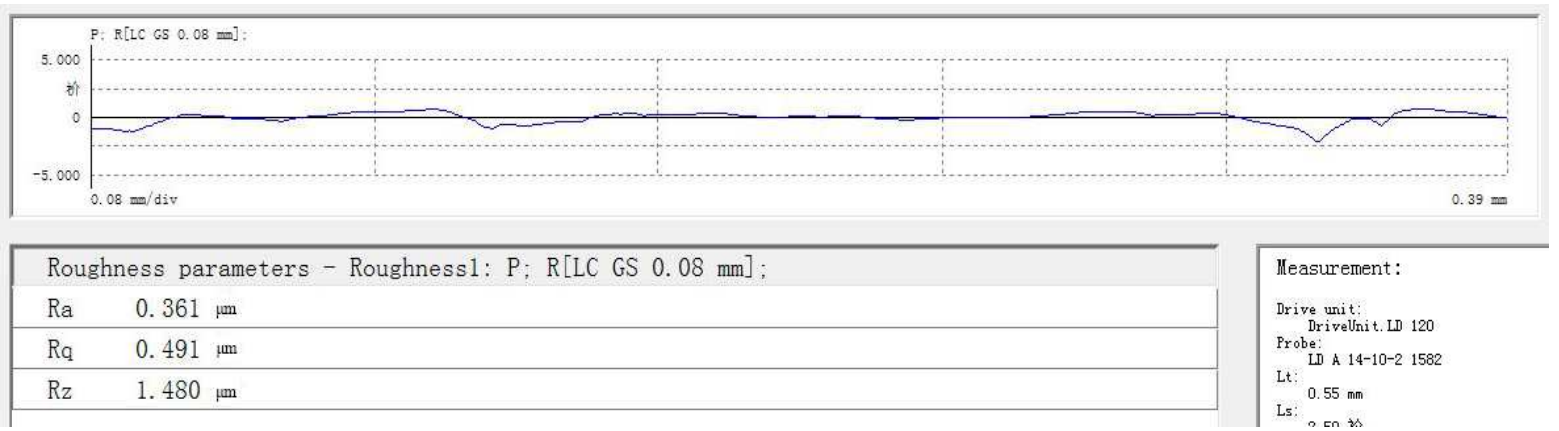

Figure 21 Tooth surface inspection diagram of surface roughness profile measuring instrument

It can be seen from Figure 20 and Figure 21 that the combination of optimized processing parameters has significantly improved the processing effect of the spur internal gear, which is manifested by good surface gloss and smooth surface. According to the surface roughness profile measuring instrument, the tooth surface roughness value has been increased from $0.380 \mu \mathrm{m}$ to $0.361 \mu \mathrm{m}$, and the ideal surface quality has been obtained. 


\section{Conclusion}

Aiming at the problem of insufficient accuracy of internal gear tooth surface machining by traditional finishing technology, And proposes the selection of abrasive flow machining technology combined with large eddy numerical simulation method to carry out numerical simulation calculation and experimental research on internal gear. The main contents and conclusions of the research are as follows:

(1) The effects of inlet velocity, abrasive concentration, and abrasive particle size on the polishing effect of internal gears in solid-liquid two-phase abrasive flow machining are discussed. The research shows that with the increase of the inlet velocity, the static pressure, and wall shear force both increase, and through the curve change graph, it can be seen that the changes of these two parameters at the inlet are particularly obvious; increasing the abrasive concentration can effectively increase the abrasive particles and The collision probability of the workpiece wall surface improves the processing efficiency and surface finish; under different abrasive particle size conditions, the smaller the abrasive mesh number, the greater the shear force of the abrasive particles on the wall surface, and the better the surface processing effect of the spur internal gear.

(2) The designed orthogonal test table is used for processing and testing, and the optimal process parameters for internal gear processing by solid-liquid two-phase abrasive flow are obtained through analysis. The research shows (1)According to the test results, it is found that the tooth surface roughness of the straight tooth internal gear reaches $3.918 \mu \mathrm{m}$ when it is not processed. After the processing is completed, the minimum value of the tooth surface roughness of the straight tooth internal gear is one order of magnitude smaller, reaching $0.380 \mu \mathrm{m}$, Effectively improve the quality of the tooth surface of the straight tooth internal gear, reduce the surface roughness, and ensure the working performance of the straight tooth internal gear. (2)Analyze the obtained test data, and obtain the optimal combination of processing parameters: inlet velocity is $60 \mathrm{~m} / \mathrm{s}$, abrasive concentration is $40 \%$, abrasive particle size is 400 meshes, and the number of processing is 40 times; four factors affect the test processing The order of the degree of influence of the results is: inlet velocity $>$ processing times $>$ abrasive concentration $>$ abrasive particle size. (3)Using the optimized processing parameter combination to optimize the processing test of the spur internal gear. 
According to the surface roughness profile measuring instrument, the tooth surface roughness value was increased from $0.380 \mu \mathrm{m}$ to $0.361 \mu \mathrm{m}$, and the ideal surface quality was obtained.

\section{Acknowledgement}

The authors would like to thank the jilin province science and technology development program of Jilin province No.20200301040RQ, Changchun science and technology program of Changchun city No. 18DY017.

\section{Authors' contributions}

Tiangang Zou designed and performed the manuscript, analyzed the data, and drafted the manuscript. Qingdong Yan and Lixiong Wang analyzed the data and supervised this study. Yuanyuan An conceived the project, and Jiyong Qu and Junye Li organized the paper and edited the manuscript. All authors read and approved the manuscript

\section{Declarations}

Ethical approval Not applicable.

Consent to participate Not applicable.

Consent to publication All presentations of case reports have consent for publication.

Conflict of interest The authors declare they have no conflict of interest.

\section{References}

[1] Bodzás S (2020) Designing and loaded tooth contact analysis of an Archimedean wor $\mathrm{m}$ gear drive focusing for the connecting teeth of the worm wheel by loaded torques. Me chanics \& Industry 21:405. https://doi.org/10.1051/meca/2020024

[2] Jin M, Islam MR, Li L, Rahman MH (2020) Contact stress and bending stress calcula tion model of spur face gear drive based on orthogonal test. Microsyst Technol 26:1055-1 065. https://doi.org/10.1007/s00542-019-04630-w

[3] Kurokawa S, Utsunomiya Y, Hayashi T, et al (2019) Whole outline scanning measure ment of internal gear by using CNC gear measuring machine. MATEC Web Conf 287:080 01. https://doi.org/10.1051/matecconf/201928708001

[4] Fu Y, Gao H, Yan Q, et al (2020) Rheological characterisation of abrasive media and finishing behaviours in abrasive flow machining. Int J Adv Manuf Technol 107:3569-3580. https://doi.org/10.1007/s00170-020-05288-9

[5] Du Y, Zhao X, He L (2019) Numerical Simulation of Tool Edge Preparation by GasSolid Two-phase Abrasive Flow. Modular Machine Tool \& Automatic Manufacturing Tech nique 05:142-145+151. https://doi.org/10.13462/j.cnki.mmtamt.2019.05.035

[6] Ji S, Li J, Tan D (2018) Pressure fluctuation analysis of softness abrasive flow based on Hilbert-Huang transtable in finishing flow channel. Journal of Mechanical \& Electrical Engineering, 35(04):335-340. https://doi.org/10.3969/j.issn.1001-4551.2018.04.001 
[7] Fu Y, Gao H, Yan Q, et al (2020) An efficient approach to improving the finishing $\mathrm{p}$ roperties of abrasive flow machining with the analyses of initial surface texture of workpie ce. Int J Adv Manuf Technol 107:2417-2432. https://doi.org/10.1007/s00170-020-05173-5

[8] Suzuki H, Oohashi K (2018) Special issue on precision abrasive technology of difficul t-to-machine materials. International Journal of Automation Technology 12:861. https://doi.o rg/10.20965/ijat.2018.p0861

[9]Wu L, Li Y (2005) Progress of Abrasive Flow Machining. Diamond \& Abrasives Engi neering, 01:69-74. https://doi.org/10.13394/j.cnki.jgszz.2005.01.020

[10] Duval-Chaneac MS, Han S, Claudin C, et al (2018) Experimental study on finishing of internal laser melting (SLM) surface with abrasive flow machining (AFM). Precision En gineering 54:1-6. https://doi.org/10.1016/j.precisioneng.2018.03.006

[11] Munhoz MR, Dias LG, Breganon R, et al (2020) Analysis of the surface roughness obtained by the abrasive flow machining process using an abrasive paste with oiticica oil. Int J Adv Manuf Technol 106:5061-5070. https://doi.org/10.1007/s00170-019-04920-7

[12] Tang Y, Zhang H, Li W, et al (2019) Abrasive Flow Polishing Refining Process and Application on Deep Hole Drilling Surface. Tool Engineering 53(08):93-97. https://doi.org/ 10.3969/j.issn.1000-7008.2019.08.019

[13] Wang L (2004) Large eddy simulation theory and its application. Journal of Hohai U niversity(Natural Sciences) 3:261-265. https://doi.org/10.3321/j.issn:1000-1980.2004.03.005.

[14] Milici B, De Marchis M, Napoli E (2020) Large eddy simulation of inertial particles dispersion in a turbulent gas-particle channel flow bounded by rough walls. Acta Mech 23 1:3925-3946. https://doi.org/10.1007/s00707-020-02740-5

[15] Bouland C, Urlea V, Beaubier K, et al (2019) Abrasive flow machining of laser pow der bed-fused parts: Numerical modeling and experimental validation. Journal of Materials Processing Technology 273:116262. https://doi.org/10.1016/j.jmatprotec.2019.116262

[16] Li J, Zhu Z, Wang B, et al (2020) Elbow precision machining technology by abrasiv e flow based on direct Monte Carlo method. J Cent South Univ 27:3667-3683. https://doi. org/10.1007/s11771-020-4562-0

[17] $\mathrm{Li} \mathrm{J}$, Zhu Z, Hu J, et al (2020) Particle collision-based abrasive flow mechanisms in precision machining. Int J Adv Manuf Technol 110:1819-1831. https://doi.org/10.1007/s001 70-020-05974-8

[18] Li J, Hu J, Yang Z, et al (2018) Effect of the size of discrete phase abrasive particl es on the abrasive flow polishing quality of common rail pipe. Journal of Jilin University (Engineering and Technology Edition) 48(02):492-499. https://doi.org/10.13229/j.cnki.jdxbgxb 20170083

[19] Ramírez-Cruz J, Salinas-Vázquez M, Ascanio G, et al (2020) Mixing dynamics in an uncovered unbaffled stirred tank using Large-Eddy Simulations and a passive scalar transp ort equation. Chemical Engineering Science 222:115658. https://doi.org/10.1016/j.ces.2020.11 5658

[20] Long Y, Han C, Ji B, et al (2020) Verification and validation of large eddy simulati ons of turbulent cavitating flow around two marine propellers with emphasis on the skew angle effects. Applied Ocean Research 101:102167. https://doi.org/10.1016/j.apor.2020.10216 7 